\title{
Fluoride exposure and duration and quality of sleep in a Canadian population-based sample
}

\author{
Jasmyn E. A. Cunningham ${ }^{1 *}$ (D) Hugh McCague ${ }^{2}$, Ashley J. Malin ${ }^{3}$, David Flora ${ }^{4}$ and Christine Till ${ }^{4}$
}

\begin{abstract}
Background: Fluoride from dietary and environmental sources may concentrate in calcium-containing regions of the body such as the pineal gland. The pineal gland synthesizes melatonin, a hormone that regulates the sleepwake cycle. We examined associations between fluoride exposure and sleep outcomes among older adolescents and adults in Canada.

Methods: We used population-based data from Cycle 3 (2012-2013) of the Canadian Health Measures Survey. Participants were aged 16 to 79 years and 32\% lived in communities supplied with fluoridated municipal water. Urinary fluoride concentrations were measured in spot samples and adjusted for specific gravity (UF $F_{S G} n=1303$ ) and water fluoride concentrations were measured in tap water samples among those who reported drinking tap water $(n=1016)$. We used multinomial and ordered logistic regression analyses (using both unweighted and survey-weighted data) to examine associations of fluoride exposure with self-reported sleep outcomes, including sleep duration, frequency of sleep problems, and daytime sleepiness. Covariates included age, sex, ethnicity, body mass index, chronic health conditions, and household income.
\end{abstract}

Results: Median (IQR) UF $\mathrm{SG}_{\mathrm{SG}}$ concentration was $0.67(0.63) \mathrm{mg} / \mathrm{L}$. Median (IQR) water fluoride concentration was 0.58 $(0.27) \mathrm{mg} / \mathrm{L}$ among participants living in communities supplied with fluoridated municipal water and 0.01 (0.06) $\mathrm{mg} / \mathrm{L}$ among those living in non-fluoridated communities. A $0.5 \mathrm{mg} / \mathrm{L}$ higher water fluoride level was associated with 34\% higher relative risk of reporting sleeping less than the recommended duration for age [unweighted: $\mathrm{RRR}=1.34,95 \% \mathrm{Cl}: 1.03,1.73 ; p=.026]$; the relative risk was higher, though less precise, using survey-weighted data [RRR $=1.96,95 \% \mathrm{Cl}: 0.99,3.87 ; p=.05] . \mathrm{UF}_{\mathrm{SG}}$ was not significantly associated with sleep duration. Water fluoride and $U_{\mathrm{SG}}$ concentration were not significantly associated with frequency of sleep problems or daytime sleepiness.

Conclusions: Fluoride exposure may contribute to sleeping less than the recommended duration among older adolescents and adults in Canada.

Keywords: Fluoride, Sleep, Canada, Adolescent, Adult, Drinking water

\footnotetext{
* Correspondence: cunninje@mcmaster.ca

${ }^{1}$ Michael G. DeGroote School of Medicine, McMaster University, Hamilton, Ontario, Canada

Full list of author information is available at the end of the article
}

(c) The Author(s). 2021 Open Access This article is licensed under a Creative Commons Attribution 4.0 International License, which permits use, sharing, adaptation, distribution and reproduction in any medium or format, as long as you give appropriate credit to the original author(s) and the source, provide a link to the Creative Commons licence, and indicate if changes were made. The images or other third party material in this article are included in the article's Creative Commons licence, unless indicated otherwise in a credit line to the material. If material is not included in the article's Creative Commons licence and your intended use is not permitted by statutory regulation or exceeds the permitted use, you will need to obtain permission directly from the copyright holder. To view a copy of this licence, visit http://creativecommons.org/licenses/by/4.0/ The Creative Commons Public Domain Dedication waiver (http://creativecommons.org/publicdomain/zero/1.0/) applies to the data made available in this article, unless otherwise stated in a credit line to the data. 


\section{Introduction}

Inorganic fluoride can naturally occur in the environment or be introduced through industrial processes or fluoride supplementation programs. A primary method of fluoride supplementation is community water fluoridation, which refers to the practice of adding fluoridation chemicals to drinking water for the purpose of controlling dental caries. Ingestion of fluoridated drinking water is a major source of fluoride intake [1,2].

As of 2017, approximately 39\% of Canadians received fluoridated water via public water systems, with the highest fluoridation rates being in Ontario and Manitoba [3]. At appropriate levels, fluoride in drinking water has consistently been shown to be associated with reduced dental caries in children $[1,4]$, reducing tooth decay by approximately 30 to $40 \%$ [5]. Excess fluoride intake in early life has been associated with enamel fluorosis [4], though increased risk of neurodevelopmental toxicity has been recently reported in populations exposed to optimal fluoride levels [6, 7]. Currently, the maximum acceptable concentration (MAC) of fluoride in drinking water in Canada is $1.5 \mathrm{mg} / \mathrm{L}$, with an optimal water fluoride target of $0.7 \mathrm{mg} / \mathrm{L}$ to maximize dental benefits while minimizing fluorosis [8].

In 2006, the National Research Council (NRC) conducted a comprehensive review of the health effects of fluoride exposure [9]. One conclusion was that fluoride is likely to affect pineal functioning, and may cause a decrease in melatonin production [9]. The pineal gland is a small neuroendocrine organ situated near the center of the brain. It sits outside of the blood-brain barrier, and thus the passage of fluoride is not restricted as it is in other areas of the brain. Its tissue is subject to mineralization, with calcification producing concretions up to several millimeters in diameter [10]. This calcification consists of hydroxyapatite, similar to that of bones or teeth [11-13]. It has been found to accumulate high levels of fluoride [10] even from low fluoride consumption due to fluoride's high affinity for hydroxyapatite [12]. This vulnerability could increase the risk of pineal gland fluoride toxicity [13, 14]. In older individuals, fluoride measurements in the pineal gland have been shown to be roughly equivalent to those in teeth [10].

The pineal gland's primary function is to synthesize melatonin during the dark portion of the day-night cycle to help maintain normal sleep and circadian rhythms. Melatonin is suppressed by light to the retina and its secretion is controlled by the circadian timing system driven by the circadian pacemaker, the suprachiasmatic nucleus [15]. Given fluoride's propensity to accumulate in the pineal gland [10, 12], along with the wellestablished relationships of the degree of pineal gland calcification with human melatonin levels [16-18] and disruption to various sleep-related outcomes (including
REM sleep percentage, total sleep time, sleep efficiency, daytime tiredness, and sleep disturbance) $[18,19]$, further research is needed examining the potential for fluoride to impact sleep outcomes. To date, only one study has investigated the association between fluoride exposure and sleep [20]; none have examined this association in adult humans.

Our study examined the association between fluoride exposure and sleep outcomes in a large Canadian sample using cross-sectional data from Cycle 3 (2012-2013) of the Canadian Health Measures Survey (CHMS). Specifically, we assessed the associations of fluoride concentrations in household tap water and urinary spot samples with self-reported sleep outcomes, including sleep duration and frequency of sleep problems as well as daytime sleepiness. We hypothesized that greater fluoride exposure would be associated with lower-than-optimal sleep duration and an increase in sleeping problems and daytime sleepiness.

\section{Methods \\ Study participants}

This study used data from Cycle 3 (2012-2013) of the Canadian Health Measures Survey (CHMS). The CHMS randomly selected individuals ages 3 to 79 years living in Canada, excluding individuals living on reserves and Aboriginal settlements, full-time members of the Canadian Forces, institutionalized individuals, and individuals who were otherwise remote-dwelling or who lived in the northern territories. In total, 5785 respondents from 16 sites across 10 provinces were enrolled in the survey; 2671 provided urine samples (out of the approximately 2950 who were asked to do so) and 2188 provided tap water samples that were analyzed for fluoride (for more information, please see [21]) [22]. For the current study, we selected individuals who were between 16 and 79 years and had a fluoride measurement in either a tap water or urine sample $(n=1396)$ (see Additional File 1 for a participant flowchart). We included only participants over the age of 15 years because parents are less likely to set the bedtime of older adolescents [23] and we were interested in measures of sleep duration that reflect habits of participants themselves rather than sleep durations artificially imposed via parenting.

Among those with complete covariate and sleep outcome data, there were 1016 participants with fluoride concentrations measured in their tap water and 1303 participants who had urinary fluoride concentration measurements. The urinary fluoride sample $(n=1303)$ included individuals regardless of whether they drink tap water whereas the tap water sample $(n=1016)$ only included individuals if they reported drinking tap water. Of the urinary fluoride sample, 387 (29.7\%) lived in regions without community water fluoridation, 415 
(31.9\%) lived in regions with community water fluoridation, and 501 (38.5\%) lived in regions with unreported or mixed community water fluoridation (i.e. due to unclear site boundaries, only some or intermittent municipal water fluoridation). For a description of the determination of water fluoridation status in the CHMS sample, see [24].

\section{Fluoride measures}

Fluoride concentrations in urine spot samples (non-fasting; non-standard collection time; first-catch urine) were diluted with an ionic adjustment buffer and analyzed using an Orion $\mathrm{pH}$ meter with a fluoride ion selective electrode. Analyses of urine samples were completed at the Laboratoire de santé publique du Québec under standardized operating procedures [25]. For quality assurance and control protocols, see [25]. The limit of detection (LoD) for urinary fluoride was $10 \mu \mathrm{g} / \mathrm{L}$ [25]; all of the urinary fluoride values were above this LoD. Concentrations of urinary fluoride were adjusted for specific gravity $\left(\mathrm{UF}_{\mathrm{SG}} ; \mathrm{mg} / \mathrm{L}\right)$ rather than creatinine because urinary creatinine concentrations can demonstrate more variation with factors such as age, sex, ethnicity/race, body mass index (BMI), and time of day of sample collection [26-28].

Tap water samples $(\mathrm{mg} / \mathrm{L})$ were collected at participants' homes and were analyzed for fluoride by the Laboratoire de santé publique du Québec [25] using a basic anion exchange chromatography procedure with a LoD of $6 \mu \mathrm{g} / \mathrm{L}$. Values below the LoD were replaced with an imputed value of $\mathrm{LoD} / \sqrt{ } 2$ [29].

\section{Sleep measures}

Self-reported habitual sleep duration was based on participants' response to the question: How many hours do you usually spend sleeping in a $24 \mathrm{~h}$ period, excluding time spent resting? Values were recorded to the nearest half hour, with a minimum value of 1 and a maximum value of 24. Based on these values, participants were then categorized into one of three categories: lower than recommended sleep duration, recommended sleep duration, or higher than recommended sleep duration. Categories were based on the National Sleep Foundation's sleep range recommendations [30], which corresponded to age groups as follows: $8-10 \mathrm{~h}$ for teenagers aged 16 to 17 years, $7-9 \mathrm{~h}$ for adults aged 18 to 64 , and $7-8 \mathrm{~h}$ for adults aged 65 or older.

Frequency of sleep problems and frequency of daytime sleepiness were also ascertained by questionnaire. Participants responded to the questions: How often do you have trouble going to sleep or staying asleep? and How often do you find it difficult to stay awake during your normal waking hours when you want to? Both questions were answered on a five-point scale, with responses categorized as never, rarely, sometimes, most of the time, or all of the time.

\section{Covariates}

We selected covariates a priori that had theoretical relevance to sleep outcomes or fluoride exposure [31-36]. These covariates included BMI, ethnicity (white or nonwhite), total household income (log transformed), chronic health condition (yes/no), sex, and age. Examples of chronic health conditions included a heart condition, multiple sclerosis, kidney dysfunction, and use of a colostomy bag. We identified confounders by using a directed acyclic graph (DAG) (see Additional File 2).

\section{Statistical analysis}

All analyses were completed with Stata (version 15) at the Research Data Centres (RDC) at York University and McMaster University. Descriptive statistics were obtained for all exposure variables, outcome variables, and covariates. The current study reports non-weighted descriptive data because results were first released from the RDC using non-weighted data (and we are not permitted to release both weighted and non-weighted descriptive data). Subsequent analyses applied survey weights and 500 bootstrap weights to permit generalization of the findings to the entire Canadian population. Thus, we report our effect estimates using both unweighted and survey-weighted data.

Spearman correlation was used to test the relationship between $\mathrm{UF}_{\mathrm{SG}}$ and water fluoride concentration collapsing across age. Multinomial logistic regression was used to model sleep duration as a function of urinary or tap water fluoride, adjusting for covariates. Ordered logistic regression was used to model frequency of sleep problems and daytime sleepiness as a function of urinary or tap water fluoride, adjusting for covariates. Variance inflation factors indicated no concerns with multicollinearity in any of our models. We tested potential departures from linear associations between fluoride exposure and the sleep outcome logits by fitting models with quadratic terms (i.e. $\mathrm{UF}_{\mathrm{SG}}{ }^{2}$ ). We did not detect non-log-linearity of the effect estimates. We explored potentially influential cases using Cook's distance and identified a small number of cases with high water fluoride levels ranging between 2.0 to $2.5 \mathrm{mg} / \mathrm{L}$ and $\mathrm{UF}_{\mathrm{SG}}$ concentration values that were above $4 \mathrm{mg} / \mathrm{L}$. Analyses retained the high water fluoride values because they are plausible outcomes (due to some regions in Canada having naturally occurring fluoride levels that exceed the MAC level) and were not deemed influential using Cook's distance. However, we removed the small number of cases with extreme $\mathrm{UF}_{\mathrm{SG}}$ values $>4 \mathrm{mg} / \mathrm{L}$ from our primary models because there was less certainty that these values were plausible exposure values (exact number of cases not 
reported due to Statistics Canada confidentiality requirements). While these values are biologically plausible, they are more likely to represent an acute fluoride ingestion (e.g. swallowing toothpaste prior to urine sample) rather than a reliable exposure measure.

We tested potential interactions between fluoride exposure and sex, age, BMI, and ethnicity, respectively; if non-significant, the interaction term was removed. Given the wide age range, we also tested a quadratic interaction effect with age (i.e., fluoride"age ${ }^{2}$ ). A twotailed alpha of 0.05 was used as the threshold for statistical significance for all main effects as well as interactions given the large number of interactions tested and their exploratory nature. To aid interpretation, we adjusted the regression coefficients so that they represent the predicted difference in sleep outcome per $0.5 \mathrm{mg} / \mathrm{L}$ of fluoride in tap water or urine; $0.5 \mathrm{mg} / \mathrm{L}$ corresponds to the approximate difference between mean water or $\mathrm{UF}_{\mathrm{SG}}$ level among individuals living in fluoridated versus non-fluoridated regions in Canada [24]. We also present regression coefficients representing the predicted difference in sleep outcome per IQR $\mathrm{mg} / \mathrm{L}$ of fluoride in tap water or urine. Finally, we conducted the following sensitivity analyses: 1 ) we restricted the sample to adults aged 18 and up; 2) we re-ran the models with the $\mathrm{UF}_{\mathrm{SG}}$ values $>4 \mathrm{mg} / \mathrm{L}$ included.

\section{Results}

Tables 1 and 2 present descriptive statistics (unweighted) for demographic characteristics, fluoride variables, and sleep outcomes for participants included in the current study (see Additional File 1 for demographic characteristics of participants excluded because a water fluoride or urinary fluoride outcome was not collected). Urinary fluoride levels were moderately associated with water fluoride levels (Spearman correlation $=0.45$, $p<.001)$. Among the 1303 participants with urinary fluoride measurements, 858 (66\%) reported sleeping for a duration within the recommended range [30], 377 (29\%) reported sleeping less than the recommended duration and 68 (5\%) reported sleeping more. Most of the sample (combined total of 689;53\%) reported never or rarely having trouble going to sleep or staying asleep, with 308 (24\%) reporting trouble most or all of the time. Similarly, most of the sample $(n=822 ; 63 \%)$ reported never or rarely having difficulty staying awake during normal waking hours, with only 93 (7\%) reporting difficulty most or all of the time.

Multinomial logistic regression of sleep duration and water fluoride levels adjusted for covariates showed a significant association between higher water fluoride and a lower sleep duration; specifically, for every $0.5 \mathrm{mg} / \mathrm{L}$ higher water fluoride concentration, there was a $34 \%$ increased relative risk of reporting sleeping less than the recommended duration $(\mathrm{RRR}=1.34 ; 95 \% \mathrm{CI}: 1.03,1.73$; $p=.026$; Table 3 ). Water fluoride levels were not significantly associated with sleeping more than the recommended amount, frequency of trouble sleeping, or frequency of daytime sleepiness. Urinary fluoride levels were not significantly associated with any of the sleep outcomes (Table 4), except a significant age by $\mathrm{UF}_{\mathrm{SG}}$ interaction in the ordinal logistic regression described next. The pattern of results remained consistent using the weighted data (see Additional File 3, Supplemental Table 2 for the weighted coefficients). The weighted multinomial logistic regression model showed that higher water fluoride levels were associated with a higher, though less precise, relative risk of reporting sleeping less than the recommended duration $(\mathrm{RRR}=$ 1.96; 95\% CI: $0.99,3.87 ; p=.05)$. No other associations were found with water fluoride levels and sleep outcomes or with $\mathrm{UF}_{\mathrm{SG}}$ and sleep outcomes using weighted models.

In the ordinal logistic regression, age modified the association between $\mathrm{UF}_{\mathrm{SG}}$ and frequency of sleep difficulties $(p$ interaction $=.046)$. The nature of the interaction was such that the predicted $\mathrm{UF}_{\mathrm{SG}}$ association decreased as age increased. Specifically, for a hypothetical participant at the first age quartile (i.e., 26 years), the predicted OR was 1.17, indicating that the odds of reporting a higher level of sleep difficulties was greater with higher levels of $\mathrm{UF}_{\mathrm{SG}}$ among younger participants; for a participant at the median age (i.e., 40 years), the predicted OR was 1.03 , indicating a weak positive association between $\mathrm{UF}_{\mathrm{SG}}$ and the likelihood of increased sleep difficulties; for a hypothetical participant at the third age quartile (i.e., 60 years), the predicted OR was 0.85 , indicating that higher levels of $\mathrm{UF}_{\mathrm{SG}}$ were associated with a lower likelihood of increased sleep difficulties. There were no other significant interactions between age and $\mathrm{UF}_{\mathrm{SG}}$ (interaction for sleep duration $p=.25$; interaction for daytime sleepiness $p=.10$ ) or age and water fluoride concentration (interaction for under-sleeping $p=.72$ and oversleeping $p=.78$; interaction for sleep difficulties $p=.73$; interaction for daytime sleepiness $p=.95$ ). There were no significant interactions between sex and fluoride variables, ethnicity and fluoride variables, and BMI and fluoride variables $(p>0.05$ in all cases).

The findings did not change appreciably when we restricted the water fluoride and $\mathrm{UF}_{\mathrm{SG}}$ samples to people aged 18 and up (Supplemental Tables 3 and 4). Likewise, the results remained consistent when we included the $\mathrm{UF}_{\mathrm{SG}}$ values $>4 \mathrm{mg} / \mathrm{L}$ in predicting sleep outcomes (Supplemental Table 4).

\section{Discussion}

We investigated the association between fluoride exposure and several sleep outcomes in a large population- 
Table 1 Demographic characteristics and sleep outcomes according to urinary fluoride and water fluoride samples (unweighted data shown ${ }^{\mathrm{a}}$ )

\begin{tabular}{|c|c|c|}
\hline & $\begin{array}{l}\text { Urinary fluoride sample } \\
(n=1303)\end{array}$ & $\begin{array}{l}\text { Water fluoride sample } \\
(n=1016)\end{array}$ \\
\hline \multicolumn{3}{|l|}{ Demographic characteristics } \\
\hline Age (years); mean (SD) & $42.4(19.0)$ & $43.3(18.6)$ \\
\hline Total household income (Canadian dollars); Mean (SD) & $83,868(65,489)$ & $87,293(66,421)$ \\
\hline \multicolumn{3}{|l|}{ Ethnicity; n (\%) } \\
\hline White & $1052(80.7)$ & $812(79.9)$ \\
\hline Non-white & $251(19.3)$ & $204(20.1)$ \\
\hline \multicolumn{3}{|l|}{ Sex; n (\%) } \\
\hline Female & $669(51.3)$ & $515(50.7)$ \\
\hline Male & $634(48.7)$ & $501(49.3)$ \\
\hline \multicolumn{3}{|l|}{ BMI category; n (\%) } \\
\hline Underweight & $39(3.0)$ & $30(3)^{b}$ \\
\hline Normal weight & $507(38.9)$ & $417(41)^{\mathrm{b}}$ \\
\hline Overweight & $434(33.3)$ & $345(34)^{b}$ \\
\hline Obese & $323(24.8)$ & $224(22)^{b}$ \\
\hline \multicolumn{3}{|l|}{ Water fluoridation status; n (\%) } \\
\hline Not fluoridated & $387(29.7)$ & 309 (30.4) \\
\hline Fluoridated & $415(31.9)$ & $342(33.7)$ \\
\hline Missing or mixed fluoridation & $501(38.5)$ & 365 (35.9) \\
\hline \multicolumn{3}{|l|}{ Sleep outcomes } \\
\hline \multicolumn{3}{|l|}{ Sleep duration; n (\%) } \\
\hline Lower than recommended & 377 (28.9) & $290(28.5)$ \\
\hline Within recommended ${ }^{c}$ & $858(65.9)$ & $677(66.6)$ \\
\hline Higher than recommended & $68(5.2)$ & $49(4.8)$ \\
\hline \multicolumn{3}{|l|}{ Trouble sleeping; n (\%) } \\
\hline Never & 389 (29.9) & $317(31.2)$ \\
\hline Rarely & $300(23.0)$ & $246(24.2)$ \\
\hline Sometimes & $306(23.5)$ & $217(21.4)$ \\
\hline Most of the time & $187(14.4)$ & $143(14.1)$ \\
\hline All of the time & $121(9.3)$ & $93(9.2)$ \\
\hline \multicolumn{3}{|l|}{ Trouble staying awake; n (\%) } \\
\hline Never & $439(33.7)$ & $344(33.9)$ \\
\hline Rarely & $383(29.4)$ & $313(30.8)$ \\
\hline Sometimes & $388(29.8)$ & $291(28.6)$ \\
\hline Most of the time & $73(5.6)$ & $68(6.7)^{d}$ \\
\hline All of the time & $20(1.5)$ & d \\
\hline
\end{tabular}

${ }^{a}$ As directed by Statistics Canada, we are not permitted to report both non-weighted and population-weighted descriptive data. Abbreviations: BMI body mass index, SD standard deviation. ${ }^{b}$ Approximate sample sizes and rounded percentages reported due to confidentiality requirements by Statistics Canada. ${ }^{c} \mathrm{Categories}$ based on the National Sleep Foundation's recommendations [30]: 8-10 h if ages 16 to 17 years, 7-9 h if ages 18 to $64,7-8 \mathrm{~h}$ if ages 65 or older. ${ }^{\mathrm{d}}$ Categories Most of the time and All of the time were collapsed due to confidentiality requirements by Statistics Canada (value reflects number of participants reporting either response)

based sample of older adolescents and adults, using Cycle 3 (2012-2013) of the Canadian Health Measures Survey. As of 2017, approximately $39 \%$ of Canadians had access to fluoridated water [3]; in our sample, approximately $32 \%$ lived in regions with community water fluoridation, 30\% lived in regions without water fluoridation, and $38 \%$ lived in areas of mixed community water fluoridation or had missing data.

We found that for every $0.5 \mathrm{mg} / \mathrm{L}$ higher water fluoride concentration, there is a $34 \%$ increased relative risk 
Table 2 Descriptive statistics for fluoride measures (unweighted data shown)

\begin{tabular}{lllllll}
\hline & N & Mean & SD & 25th percentile & 50th percentile & 75th percentile \\
\hline Urinary fluoride, adjusted for specific gravity $(\mathrm{mg} / \mathrm{L})$ & 1303 & 0.86 & 0.62 & 0.46 & 0.67 & 1.08 \\
Tap water fluoride $(\mathrm{mg} / \mathrm{L})$ & 1016 & 0.24 & 0.26 & 0.06 & 0.12 & 0.44 \\
$\quad$ Fluoridated & 342 & 0.52 & 0.22 & 0.42 & 0.58 & 0.69 \\
$\quad$ Non-fluoridated & 309 & 0.05 & 0.15 & 0.01 & 0.01 & 0.07 \\
$\quad$ Mixed or unknown & 365 & 0.14 & 0.11 & 0.09 & 0.11 & 0.14 \\
\hline
\end{tabular}

of reporting sleeping less than the recommended amount. This result suggests that higher fluoride exposure is associated with sleep deficits in older adolescents and adults. The association between higher water fluoride concentration and sleeping less remained consistent if we restrict the sample to those aged 18 and older (RRR = 1.32). Using weighted data, we found an even stronger, though less precise, association between water fluoride concentration and sleeping less $(R R R=1.96)$. Among individuals aged 16 and older, we found that approximately $29 \%$ of individuals reported sleeping less than the recommended duration. This proportion of individuals reporting low habitual sleep durations is consistent with a larger sample of 10,976 adult respondents of the CHMS of which $32 \%$ reported sleeping less than the recommended duration [36]. Insufficient sleep is associated with various adverse outcomes, including changes in mood [37-40], cognition [37, 40-42], and reaction time [40, 43, 44], higher rates of motor vehicle accidents [45], hypertension, cardiovascular disease [46-48], and diabetes [47].

While the direction of causality cannot be discerned due to the cross-sectional nature of the survey, we can provide some hypotheses to explain the finding. Given the tendency of fluoride to accumulate in the pineal gland, the association between fluoride exposure and shorter sleep duration may be explained by an effect on melatonin production and subsequently the timing of sleep. In humans, the pineal gland is subject to calcification and forms concretions. This calcification varies between individuals, but generally increases with age $[9,49]$. Sympathetic nervous system innervation forms the major communication between the pineal gland and the superior cervical ganglion $[9,50]$ and may also serve to maintain these concretions [49]. Additionally, these concretions may reflect prior biosynthetic metabolic activity of the gland, resulting from dark exposure, for example [49]. Fluoride accumulates in the pineal gland to a similar degree as in teeth [10] and the pineal gland in older individuals contains more fluoride than any other soft tissue [49]. This accumulation is likely due to fluoride's high affinity for hydroxyapatite [12], as pineal fluoride concentration is directly correlated with pineal calcium concentration [10, 49], as well as the fact that it sits outside of the blood brain barrier, has a substantial blood supply [13], and may be 'sampling' the blood in circulation [49]. One study found that the association between pineal fluoride and calcium was very strong $\left(r^{2}=0.92\right)$ only for pineal glands with high levels of fluoride, which implies that high pineal fluoride is associated with increased calcification $[12,13]$. The deposition of fluoride in calcified tissues, such as the pineal gland, bones, and teeth, may represent a defense mechanism against potential fluoride toxicity (in other tissues), which may begin in the prenatal period [13].

Fluoride deposition in the pineal gland and its calcification would most likely exert effects on sleep via changes to pinealocytes and subsequently melatonin output. The pineal gland is composed primarily of pinealocytes, which synthesize melatonin $[13,50]$. Pinealocyte calcification is not directly correlated with decreased plasma melatonin; however, it is associated with a decreased number of pinealocytes [13]. Therefore, pinealocyte calcification likely has indirect effects on melatonin

Table 3 Adjusted associations between water fluoride concentration and sleep measures $(n=1016)$

\begin{tabular}{|c|c|c|c|}
\hline \multirow[t]{2}{*}{ Outcome } & \multicolumn{2}{|c|}{ Association $(95 \% \mathrm{Cl})$ for change in outcome per: } & \multirow[t]{2}{*}{$p$} \\
\hline & $0.5 \mathrm{mg} / \mathrm{L}$ & IQR $(0.38 \mathrm{mg} / \mathrm{L})$ & \\
\hline \multicolumn{4}{|l|}{ Sleep Duration ${ }^{a}$} \\
\hline Less than recommended & $1.34(1.03,1.73)$ & $1.25(1.03,1.51)$ & .03 \\
\hline Recommended (ref) & - & - & \\
\hline More than recommended & $0.95(0.53,1.71)$ & $0.96(0.61,1.50)$ & .86 \\
\hline Trouble Sleeping ${ }^{b}$ & $0.95(0.77,1.18)$ & $0.97(0.82,1.13)$ & .67 \\
\hline Daytime Sleepiness ${ }^{b}$ & $1.16(0.94,1.44)$ & $1.12(0.95,1.32)$ & .17 \\
\hline
\end{tabular}


Table 4 Adjusted associations between specific-gravity adjusted urinary fluoride concentration and sleep measures $(n=1303)$

\begin{tabular}{|c|c|c|c|}
\hline \multirow[t]{2}{*}{ Outcome } & \multicolumn{2}{|c|}{ Association $(95 \% \mathrm{Cl})$ for change in outcome per: } & \multirow[b]{2}{*}{$p$} \\
\hline & $0.5 \mathrm{mg} / \mathrm{L}$ & IQR $(0.62 \mathrm{mg} / \mathrm{L})$ & \\
\hline \multicolumn{4}{|l|}{ Sleep Duration ${ }^{a}$} \\
\hline Less than recommended & $1.02(0.93,1.13)$ & $1.02(0.94,1.10)$ & 64 \\
\hline Recommended (ref) & - & - & \\
\hline More than recommended & $0.91(0.74,1.13)$ & $0.93(0.80,1.10)$ & .40 \\
\hline Trouble Sleeping $^{b}$ & $0.96(0.89,1.04)$ & $0.97(0.91,1.03)$ & .37 \\
\hline Daytime Sleepiness ${ }^{\mathrm{b}}$ & $1.00(0.92,1.08)$ & $1.00(0.94,1.06)$ & .95 \\
\hline
\end{tabular}

Relative risk ratios (RRR)

bodds Ratio (OR)

biosynthesis, as the degree of uncalcified pineal tissue is associated with plasma and saliva melatonin $[13,16,17]$. Calcification of the pineal gland may also lead to decreased levels of melatonin in the cerebrospinal fluid [13]. Fluoride has been shown to affect pinealocytes and melatonin in animal models; for example, adult rats showed a 73\% increase in these cells after 8 weeks of a fluoride-free diet compared to rats consuming standard fluoridated food and water [14], and a doctoral dissertation showed that prepubescent gerbils receiving a diet high in fluoride had lower melatonin production than those receiving a low-fluoride diet [49]. To our knowledge, there are no studies in living humans on the direct effects of fluoride exposure on the pineal gland or melatonin production and secretion.

These changes in calcification and melatonin excretion are a credible means through which fluoride could impact sleep and circadian outcomes. Calcification of the pineal gland has been shown to be associated directly with sleep complaints, including daytime tiredness and sleep disturbance [19], as well as decreased REM sleep percentage, total sleep time, and sleep efficiency on polysomnographic measurement [18]. Higher uncalcified pineal volume has been associated with less sleep rhythm disturbance, even in otherwise 'good sleepers' [16]. Changes in melatonin onset time, peak time, and peak concentration have been associated with sleep disturbances, specifically sleep efficiency [51], and a delay in endogenous melatonin rhythms compared to normal individuals is what typically leads to the clinical manifestation of delayed sleep phase syndrome (DSPS). For individuals with DSPS, exogenous melatonin administration can be an effective means of ameliorating symptoms, by advancing sleep onset and wake times [52]. Alternatively, it is possible that fluoride could directly inhibit enzymes required for melatonin synthesis [13]. Together, these findings imply that a smaller or more calcified pineal gland and subsequent decreased melatonin output could be a risk factor for circadian instability and/or sleep and sleep rhythm disturbances.
Another possible mechanism through which fluoride could exert effects on the central nervous system, including sleep outcomes, is through oxidative stress. Fluoride can be a source of oxidative stress and may induce generation of reactive oxygen species (ROS) and lipid peroxidization [13, 53, 54]. Melatonin and other proteins from the pineal gland act as antioxidants [54]. Therefore, as the pineal gland calcifies and there is decreased melatonin output, there may be increased activity of these ROS and subsequent neural damage [13]. Further research should be conducted to elucidate this potential pathway. Alternatively, mechanisms outside of the pineal gland may be responsible for our findings; for example, hypothyroidism $[55,56]$ or hypertension $[57$, 58 ] could potentially influence the relationship between fluoride exposure and short sleep duration. These health conditions could possibly be on the causal pathway that mediates the association between fluoride exposure and sleep duration.

As far as we are aware, this is only the second human study investigating the effects of fluoride exposure on sleep outcomes, and the first study with an adult sample. Fluoride exposure has been associated with later bed and wake times in 16-to-19 year olds [20]; if participants went to bed later due to a delayed onset of nighttime sleepiness, but were constrained from a later wake time due to conflicting commitments (work, school, etc.), this situation could contribute to a shortened sleep duration as seen in the present study. However, given that our sample included mainly adults (and only adults when we restricted the sample to those aged 18 and older), this generalization from results found in older adolescents should be made cautiously. Additionally, the present study did not include a measure of sleep timing, so we were unable to test this hypothesis. Future studies should continue to investigate effects of fluoride exposure on sleep timing in adults.

Although we found an association between water fluoride and sleep duration, we did not find any associations between measures of fluoride exposure and our other sleep outcomes (frequency of daytime sleepiness 
or sleep problems). There are several potential reasons for these findings. It is possible that fluoride primarily leads to a disturbance in melatonin secretion in the form of a delay, as outlined above, or to a direct shortening of total sleep time, either of which could manifest as a shortened sleep duration but without accompanying daytime sleepiness or nighttime sleep disturbance. Alternatively, our measurements of sleep outcomes were rudimentary (comprised of a single question capturing each sleep outcome), and it is possible that they were not sensitive enough to capture various sleep pathologies. For example, the question assessing daytime sleepiness asks about difficulty staying awake; participants may have experienced more moderate daytime sleepiness, which would not necessarily have been captured in our data. Similarly, participants would likely not have been aware of disturbances in their sleep architecture (i.e. sleep problems), and our dataset would therefore not include this information. Future research should investigate the relationship between fluoride exposure and sleep using both objective (e.g. polysomnography, actigraphy, dim light melatonin onset) and validated subjective measures (e.g. Pittsburgh Sleep Quality Index [59], Stanford Sleepiness Scale [60]) to better characterize the nature of any sleep and circadian disturbances.

One limitation of this study is that we were unable to account for the presence of sleep disorders or other behaviors that could impact sleep (e.g. exercise, diet, use of melatonin supplements, sleeping pills, or medications). Future studies should investigate the relationship between fluoride exposure, sleep, and these factors; the relationship with physical activity is of particular interest given that a pilot study found that vigorous exercise in adults is associated with a reduction in renal fluoride clearance and an increased trend in plasma fluoride concentration [61]. This could potentially lead to greater uptake by body tissue [62], though this study of mice found no link between chronic exercise and bone fluoride levels. While we did not account for physical activity in our study, we did include BMI as a covariate, which is associated with physical activity levels [63]. Additionally, because our study is cross-sectional, the direction of the association between fluoride exposure and sleep outcomes is not established. Given these limitations and the limited evidence on the topic to date, the results of our study should be viewed as hypothesis-generating.

A strength of our study is that we included two measurements of fluoride exposure: tap water fluoride and specific-gravity adjusted urinary fluoride levels. Our results demonstrate that while water fluoride level was significantly associated with a lower than recommended sleep duration, $\mathrm{UF}_{\mathrm{SG}}$ was not. This finding is consistent with two other population-based fluoride studies [20,
24], both of which found that water fluoride levels but not fluoride biomarkers (i.e. plasma, urine) were associated with adverse health outcomes. Consistent with their explanation, it is likely that water fluoride measurements act as a proxy for chronic or historical fluoride exposure (assuming the individual's residence in a community with water fluoridation remains stable), whereas single urinary spot samples represent short-term (contemporaneous) exposure that may fluctuate between subsequent measurements [20]. In terms of risk to pineal gland calcification, fluoride may need time to accumulate in the pineal gland before exerting an impact on sleep. Although it is known that pineal gland calcification increases with age $[9,49]$, it is not clear whether lifetime exposure drives this relationship. One report [49] suggested that pineal fluoride does not reflect cumulative fluoride exposure of the individual due to a lack of correlation between fluoride in the pineal gland and in bone ash. However, this finding was potentially confounded by other methodological factors, such as the inclusion of bone samples from different types of bone, which have been shown to contain differing levels of fluoride $[9,10$, 49]. Moreover, we would not necessarily expect pineal and bone fluoride levels to be correlated given that fluoride is reversibly bound to bone and can be rereleased into plasma [64]. Prospective studies are needed to investigate the potential impacts of cumulative fluoride exposure across varying stages of development on sleep outcomes.

\section{Conclusions}

Higher water fluoride concentration was significantly associated with increased risk of reporting fewer than the recommended hours of sleep. This finding suggests that fluoride exposure may contribute to clinically meaningful reductions in sleep duration among individuals living in areas with optimal water fluoridation. These findings should be interpreted in the context of the demonstrated benefits of fluoride exposure for dental health $[1,4,5,8,65]$.

\section{Supplementary Information}

The online version contains supplementary material available at https://doi. org/10.1186/s12940-021-00700-7.

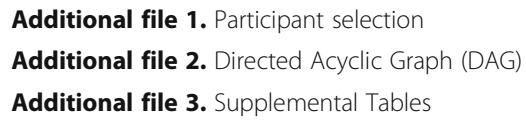

\section{Abbreviations}

BMI: Body Mass Index; CHMS: Canadian Health Measures Survey; Cl: Confidence Interval; DSPS: Delayed Sleep Phase Syndrome; IQR: Interquartile Range; LoD: Limit of Detection; MAC: Maximum Acceptable Concentration; NRC: National Research Council; RDC: Research Data Centre; ROS: Reactive Oxygen Species; RRR: Relative Risk Ratio; UF $F_{S G}$ : Urinary Fluoride adjusted for Specific Gravity 


\section{Acknowledgments}

The authors gratefully acknowledge all of the participants of the Canadian Health Measures Survey, as well as the staff at Statistics Canada who facilitated the operation and use of the survey. The authors also wish to thank Julia Riddell for classifying fluoridation status for each of the CHMS study sites.

\section{Authors' contributions}

JC: Contributed to study design; contributed to statistical analysis; contributed to interpretation of results; drafted and critically revised manuscript. HM: Supported and verified statistical analysis; contributed to interpretation of results and critical revision of the manuscript. AM: Contributed to study design and critical revision of the manuscript. DF: Verified statistical analysis; contributed to interpretation of results; contributed to critical revision of the manuscript. CT: Conceived of study idea; contributed to study design; contributed to statistical analysis; contributed to critical revision of the manuscript; supervised the project. All authors: Discussed results; commented on and approved final manuscript.

\section{Authors' information}

Not applicable.

\section{Funding}

This work was supported by a McMaster Medical Student Research Excellence Award (MAC RES) from the Michael G. DeGroote School of Medicine and a grant from the National Institutes of Environmental Health Sciences (NIEHS) (grant \#R01ES030365). This research was conducted at York University, a part of the Canadian Research Data Centre Network (CRDCN), which has received support from the Social Sciences and Humanities Research Council (SSHRC), the Canadian Institutes of Health Research (CIHR), the Canadian Foundation for Innovation (CFI), and Statistics Canada. Although the research and analysis are based on data from Statistics Canada, the opinions expressed do not represent the views of Statistics Canada. The funding sources did not have any involvement in the study or decision to submit the article for publication.

\section{Availability of data and materials}

The data from the Canadian Health Measures Survey (CHMS) Cycle 3 (20122013) analyzed during the current study are publicly available here: https:// www.statcan.gc.ca/eng/statistical-programs/document/5071_D5_T9_V1

\section{Ethics approval and consent to participate}

The present study was approved by the York University Research Ethics Board. The CHMS was reviewed and approved by the Health Canada Research Ethics Board.

\section{Consent for publication}

Not applicable.

\section{Competing interests}

The authors declare that they have no competing interests.

\section{Author details}

${ }^{1}$ Michael G. DeGroote School of Medicine, McMaster University, Hamilton, Ontario, Canada. ${ }^{2}$ Institute for Social Research, York University, Toronto, Ontario, Canada. ${ }^{3}$ Department of Environmental Medicine and Public Health, Icahn School of Medicine at Mount Sinai, New York, NY, USA. ${ }^{4}$ Faculty of Health, York University, Toronto, Ontario, Canada.

Received: 24 June 2020 Accepted: 3 February 2021

Published online: 18 February 2021

\section{References}

1. National Health and Medical Research Council. A Systematic Review of the Efficacy and Safety of Fluoridation, Part A: Review Methodology and Results. Canberra: Australian Government; 2007.

2. United States Environmental Protection Agency. Fluoride: relative source contribution analysis. Washington, D.C.: Health and Ecological Criteria Division, Office of Water; 2010.

3. Public Health Agency of Canada. The State of Community Water Fluoridation across Canada. 2017.
4. McDonagh M, Whiting P, Bradley M, Cooper J, Sutton A, Chestnutt I, et al. A systematic review of public water fluoridation. United Kingdom: University of York; 2000.

5. Slade GD, Grider WB, Maas WR, Sanders AE. Water fluoridation and dental caries in U.S. children and adolescents. J Dent Res. 2018;97(10):1122-8.

6. Bashash M, Thomas D, Hu H, Martinez-Mier EA, Sanchez BN, Basu N, et al. Prenatal fluoride exposure and cognitive outcomes in children at 4 and 612 years of age in Mexico. Environ Health Perspect. 2017;125(9):097017.

7. Green R, Lanphear B, Hornung R, Flora D, Martinez-Mier EA, Neufeld R, et al. Association between maternal fluoride exposure during pregnancy and IQ scores in offspring in Canada. JAMA Pediatr. 2019;173(10):940-8.

8. Health Canada. Findings and recommendations of the fluoride expert panel (January 2007). 2008.

9. National Research Council. Fluoride in Drinking Water: A Scientific Review of EPA's Standards. Washington, DC: The National Academies Press; 2006.

10. Luke J. Fluoride deposition in the aged human pineal gland. Caries Res. 2001;35(2):125-8.

11. Bocchi $G$, Valdre G, Valdre G. Physical, chemical, and mineralogical characterization of carbonate-hydroxyapatite concretions of the human pineal gland. J Inorg Biochem. 1993;49(3):209-20.

12. Tharnpanich $\mathrm{T}$, Johns J, Subongkot $\mathrm{S}$, Johns NP, Kitkhuandee A, Toomsan $Y$, et al. Association between high pineal fluoride content and pineal calcification in a low fluoride area. Fluoride. 2016:49(4 Pt 2):472-84.

13. Chlubek D, Sikora M. Fluoride and Pineal Gland. Appl Sci. 2020;10(8):2885.

14. Mrvelj A, Womble MD. Fluoride-Free Diet Stimulates Pineal Growth in Aged Male Rats. Biol Trace Elem Res. 2020;197(1):175-83.

15. Macchi MM, Bruce JN. Human pineal physiology and functional significance of melatonin. Front Neuroendocrinol. 2004;25(3-4):177-95.

16. Liebrich LS, Schredl M, Findeisen P, Groden C, Bumb JM, Nolte IS. Morphology and function: MR pineal volume and melatonin level in human saliva are correlated. J Magn Reson Imaging. 2014;40(4):966-71.

17. Kunz D. A new concept for melatonin deficit on pineal calcification and melatonin excretion. Neuropsychopharmacology. 1999;21(6):765-72.

18. Mahlberg R, Kienast T, Hadel S, Heidenreich JO, Schmitz S, Kunz D. Degree of pineal calcification (DOC) is associated with polysomnographic sleep measures in primary insomnia patients. Sleep Med. 2009;10(4):439-45.

19. Kunz D, Bes F, Schlattmann P, Herrmann WM. On pineal calcification and its relation to subjective sleep perception: a hypothesis-driven pilot study. Psychiatry Res. 1998;82(3):187-91.

20. Malin AJ, Bose S, Busgang SA, Gennings C, Thorpy M, Wright RO, et al: Fluoride exposure and sleep patterns among older adolescents in the United States: a cross-sectional study of NHANES 2015-2016. Environ Health. 2019;18(1):106.

21. Statistics Canada. Canadian Health Measures Survey (CHMS). Available from: https://www23.statcan.gc.ca/imdb/p2SV.pl?Function=getSurvey\&ld=136652. Updated 2014-09-10

22. Statistics Canada. Canadian health measures survey (CHMS) data user guide: cycle 3. 2015.

23. Carskadon M. In: Carskadon M, editor. Adolescent sleep patterns: biological, social, and psychological influences. New York: Cambridge University Press; 2002. p. 6-9.

24. Riddell JK, Malin AJ, Flora D, McCague H, Till C. Association of water fluoride and urinary fluoride concentrations with attention deficit hyperactivity disorder in Canadian youth. Environ Int. 2019;133(Pt B):105190.

25. Health Canada. Third report on human biomonitoring of environmental chemicals in Canada: Results of the Canadian Health Measures Survey Cycle 3 (2012-2013). 2015.

26. Barr DB, Wilder LC, Caudill SP, Gonzalez A, Needham LL, Pirkle JL. Urinary creatinine concentrations in the U.S. population: implications for urinary biologic monitoring measurements. Environ Health Perspect. 2005;113(2):192-200.

27. Nermell $B$, Lindberg AL, Rahman M, Berglund M, Persson LA, El Arifeen S, et al. Urinary arsenic concentration adjustment factors and malnutrition. Environ Res. 2008;106(2):212-8.

28. Moriguchi J, Ezaki T, Tsukahara T, Fukui Y, Ukai H, Okamoto S, et al. Decreases in urine specific gravity and urinary creatinine in elderly women. Int Arch Occup Environ Health. 2005;78(6):438-45.

29. Hornung RW, Reed LD. Estimation of average concentration in the presence of nondetectable values. Appl Occup Environ Hyg. 1990;5(1):46-51.

30. Hirshkowitz M, Whiton K, Albert SM, Alessi C, Bruni O, DonCarlos L, et al. National Sleep Foundation's updated sleep duration recommendations: final report. Sleep Health. 2015; 1(4):233-43. 
31. Martinez-Mier EA, Soto-Rojas AE. Differences in exposure and biological markers of fluoride among White and African American children. J Public Health Dent. 2010;70(3):234-40.

32. Jain RB. Concentrations of fluoride in water and plasma for US children and adolescents: data from NHANES 2013-2014. Environ Toxicol Pharmacol. 2017:50:20-31.

33. Goel N, Kim H, Lao RP. Gender differences in polysomnographic sleep in young healthy sleepers. Chronobiol Int. 2005;22(5):905-15.

34. Li J, Vitiello MV, Gooneratne NS. Sleep in Normal Aging. Sleep Med Clin. 2018;13(1):1-11.

35. Jehan S, Myers AK, Zizi F, Pandi-Perumal SR, Jean-Louis G, Singh N, et al. Sleep health disparity: the putative role of race, ethnicity and socioeconomic status. Sleep Med Disord. 2018;2(5):127-33.

36. Chaput JP, Wong SL, Michaud I. Duration and quality of sleep among Canadians aged 18 to 79. Health Rep. 2017;28(9):28-33.

37. Dinges DF, Pack F, Williams K, Gillen KA, Powell JW, Ott GE, et al. Cumulative sleepiness, mood disturbance, and psychomotor vigilance performance decrements during a week of sleep restricted to 4-5 hours per night. Sleep. 1997;20(4):267-77.

38. Short MA, Louca M. Sleep deprivation leads to mood deficits in healthy adolescents. Sleep Med. 2015;16(8):987-93.

39. Talbot LS, McGlinchey EL, Kaplan KA, Dahl RE, Harvey AG. Sleep deprivation in adolescents and adults: changes in affect. Emotion. 2010;10(6):831-41.

40. Drake CL, Roehrs TA, Burduvali E, Bonahoom A, Rosekind M, Roth T. Effects of rapid versus slow accumulation of eight hours of sleep loss. Psychophysiology. 2001;38(6):979-87.

41. Bonnet MH. Effect of sleep disruption on sleep, performance, and mood. Sleep. 1985;8(1):11-9.

42. Jackson ML, Gunzelmann G, Whitney P, Hinson JM, Belenky G, Rabat A, et al. Deconstructing and reconstructing cognitive performance in sleep deprivation. Sleep Med Rev. 2013;17(3):215-25.

43. Cunningham JEA, Jones SAH, Eskes GA, Rusak B. Acute sleep restriction has differential effects on components of attention. Front Psychiatry. 2018;9:499.

44. Jewett ME, Dijk DJ, Kronauer RE, Dinges DF. Dose-response relationship between sleep duration and human psychomotor vigilance and subjective alertness. Sleep. 1999:22(2):171-9.

45. Gottlieb DJ, Ellenbogen JM, Bianchi MT, Czeisler CA. Sleep deficiency and motor vehicle crash risk in the general population: a prospective cohort study. BMC Med. 2018;16(1):44.

46. Vgontzas AN, Liao D, Bixler EO, Chrousos GP, Vela-Bueno A. Insomnia with objective short sleep duration is associated with a high risk for hypertension. Sleep. 2009:32(4):491-7.

47. Gangwisch JE, Heymsfield SB, Boden-Albala B, Buijs RM, Kreier F, Pickering TG, et al. Sleep duration as a risk factor for diabetes incidence in a large U.S. sample. Sleep. 2007;30(12):1667-73.

48. Ayas NT, White DP, Manson JE, Stampfer MJ, Speizer FE, Malhotra A, et al. A prospective study of sleep duration and coronary heart disease in women. Arch Intern Med. 2003;163(2):205-9.

49. Luke JA. The effect of fluoride on the physiology of the pineal gland [thesis (doctoral)]. Guildford: University of Surrey; 1997.

50. Moller M, Baeres FM. The anatomy and innervation of the mammalian pineal gland. Cell Tissue Res. 2002;309(1):139-50.

51. Haimov I, Laudon M, Zisapel N, Souroujon M, Nof D, Shlitner A, et al. Sleep disorders and melatonin rhythms in elderly people. BMJ. 1994;309(6948):167.

52. Zisapel N. New perspectives on the role of melatonin in human sleep, circadian rhythms and their regulation. Br J Pharmacol. 2018;175(16):3190-9.

53. Chlubek D. Fluoride and oxidative stress. Fluoride. 2003:36(4):217-28.

54. Bharti VK, Srivastava RS. Fluoride-induced oxidative stress in rat's brain and its amelioration by buffalo (Bubalus bubalis) pineal proteins and melatonin. Biol Trace Elem Res. 2009;130(2):131-40.

55. Malin AJ, Riddell J, McCague H, Till C. Fluoride exposure and thyroid function among adults living in Canada: effect modification by iodine status. Environ Int. 2018;121(Pt 1):667-74.

56. Peckham S, Lowery D, Spencer S. Are fluoride levels in drinking water associated with hypothyroidism prevalence in England? A large observational study of GP practice data and fluoride levels in drinking water. J Epidemiol Community Health. 2015;69(7):619-24.

57. Palagini L, Bruno RM, Gemignani A, Baglioni C, Ghiadoni L, Riemann D. Sleep loss and hypertension: a systematic review. Curr Pharm Des. 2013; 19(13):2409-19.
58. Amini H, Taghavi Shahri SM, Amini M, Ramezani Mehrian M, Mokhayeri Y, Yunesian M. Drinking water fluoride and blood pressure? An environmental study. Biol Trace Elem Res. 2011;144(1-3):157-63.

59. Buysse DJ, Reynolds CF 3rd, Monk TH, Berman SR, Kupfer DJ. The Pittsburgh sleep quality index: a new instrument for psychiatric practice and research. Psychiatry Res. 1989;28(2):193-213.

60. Hoddes E, Dement W, Zarcone V. Abstracts of papers presented to the eleventh annual meeting of the Association for the Psychophysiological Study of sleep: the development and use of the Stanford sleepiness scale (SSS). Psychophysiology. 1972;9(1):150.

61. Zohoori FV, Innerd A, Azevedo LB, Whitford GM, Maguire A. Effect of exercise on fluoride metabolism in adult humans: a pilot study. Sci Rep. 2015;5:16905.

62. Amaral SL, Azevedo LB, Buzalaf MAR, Fabricio MF, Fernandes MS, Valentine RA, et al. Effect of chronic exercise on fluoride metabolism in fluorosissusceptible mice exposed to high fluoride. Sci Rep. 2018;8(1):3211.

63. Ball K, Owen N, Salmon J, Bauman A, Gore CJ. Associations of physical activity with body weight and fat in men and women. Int J Obes Relat Metab Disord. 2001;25(6):914-9.

64. Buzalaf MAR, Whitford GM. Fluoride metabolism. Monogr Oral Sci. 2011;22: 20-36.

65. Rabb-Waytowich D. Water fluoridation in Canada: past and present. J Can Dent Assoc. 2009:75(6):451-4.

\section{Publisher's Note}

Springer Nature remains neutral with regard to jurisdictional claims in published maps and institutional affiliations.
Ready to submit your research? Choose BMC and benefit from:

- fast, convenient online submission

- thorough peer review by experienced researchers in your field

- rapid publication on acceptance

- support for research data, including large and complex data types

- gold Open Access which fosters wider collaboration and increased citations

- maximum visibility for your research: over $100 \mathrm{M}$ website views per year

At $\mathrm{BMC}$, research is always in progress.

Learn more biomedcentral.com/submissions 